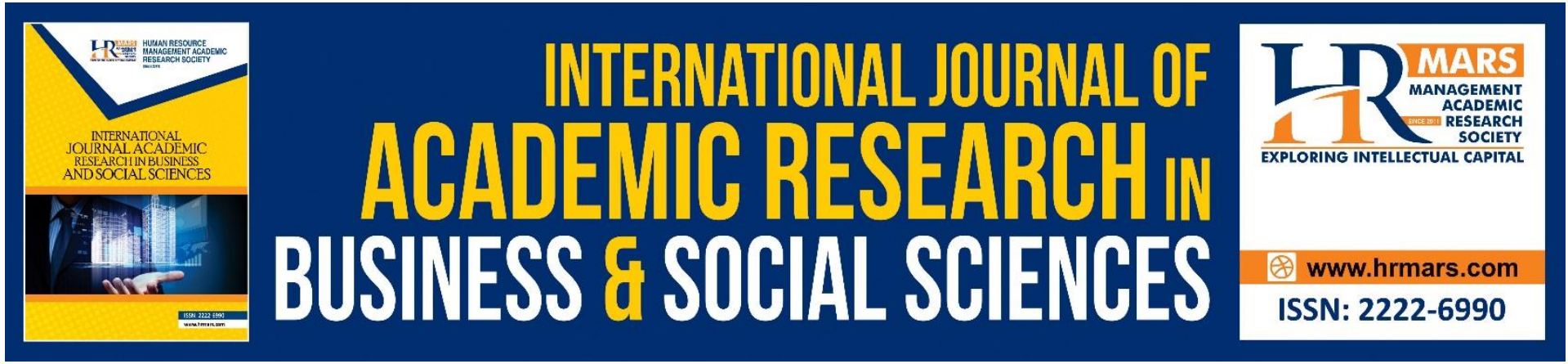

\title{
Attitude of Rehabilitation Practitioners in Conducting Juvenile Rehabilitation Programme
}

Hezzrin Mohd Pauzi, Nor Jana Saim, Norulhuda Sarnon @ Kusenin, Mohammad Rahim Kamaluddin, Wan Abd Aziz Wan Mohd Amin

To Link this Article: http://dx.doi.org/10.6007/IJARBSS/v11-i8/9860

DOI:10.6007/IJARBSS/v11-i8/9860

Received: 07 June 2021, Revised: 12 July 2021, Accepted: 01 August 2021

Published Online: 19 August 2021

In-Text Citation: (Pauzi et al., 2021)

To Cite this Article: Pauzi, H. M., Saim, N. J., Kusenin, N. S. @, Kamaluddin, M. R., \& Amin, W. A. A. W. M. (2021). Attitude of Rehabilitation Practitioners in Conducting Juvenile Rehabilitation Programme. International Journal of Academic Research in Business and Social Sciences, 11(8), 819-828.

Copyright: @ 2021 The Author(s)

Published by Human Resource Management Academic Research Society (www.hrmars.com)

This article is published under the Creative Commons Attribution (CC BY 4.0) license. Anyone may reproduce, distribute, translate and create derivative works of this article (for both commercial and non-commercial purposes), subject to full attribution to the original publication and authors. The full terms of this license may be seen at: http://creativecommons.org/licences/by/4.0/legalcode

Vol. 11, No. 8, 2021, Pg. 819 - 828

Full Terms \& Conditions of access and use can be found at http://hrmars.com/index.php/pages/detail/publication-ethics 


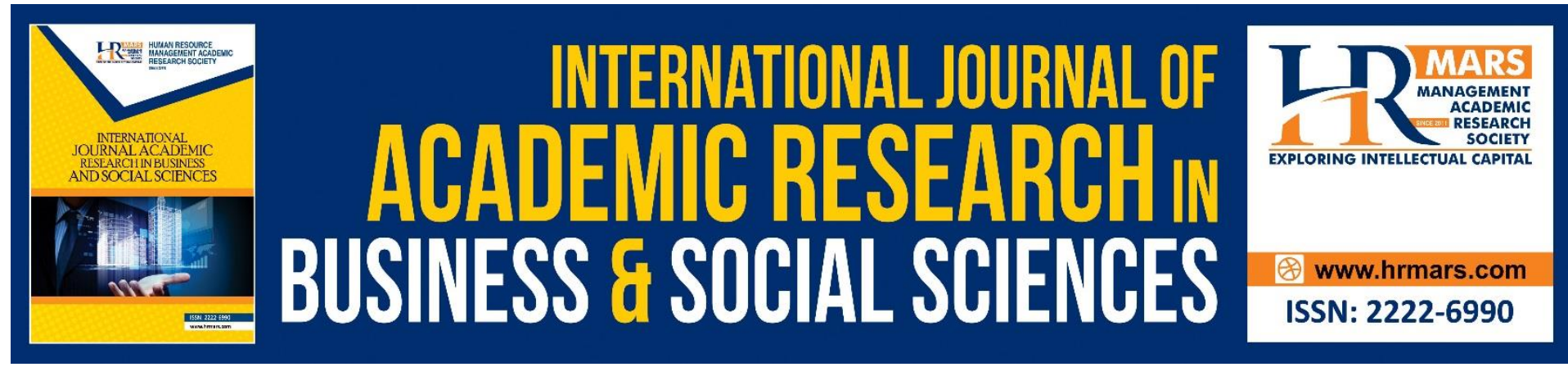

\title{
Attitude of Rehabilitation Practitioners in Conducting Juvenile Rehabilitation Programme
}

\author{
Hezzrin Mohd Pauzi ${ }^{1}$, Nor Jana Saim², Norulhuda Sarnon @ \\ Kusenin ${ }^{3}$, Mohammad Rahim Kamaluddin ${ }^{4}$, Wan Abd Aziz Wan \\ Mohd Amin ${ }^{5}$ \\ 1,5 Faculty of Applied Social Sciences, University Sultan Zainal Abidin, Gong Badak Campus, \\ 21300 Kuala Terengganu, Terengganu, Malaysia, ${ }^{2,3,4}$ Psychology and Human Well-Being \\ Research Centre, Faculty of Sciences and Humanities, University Kebangsaan Malaysia, \\ 43560 Bangi, Selangor, Malaysia.
}

\begin{abstract}
A positive rehabilitation attitude among rehabilitation practitioners is an important factor in dealing with juvenile offenders who are undergoing correctional rehabilitation programmes. However, previous studies have found that most juvenile case workers and practitioners are seen to be less knowledgeable about the attitude that needs to be exhibited when handling juveniles. The objective of this study is to evaluate the implementation of juvenile rehabilitation programmes in terms of the practices carried out by rehabilitation practitioners. The design of this study is a mixed study through a Sequential Explanatory Design. This study was conducted at a correctional rehabilitation centre in Peninsular Malaysia. The study sample consisted of rehabilitation practitioners and juveniles. Data were collected by distributing questionnaires and conducting interview sessions. Quantitative data analysis was performed using SPSS software and qualitative data were analysed through thematic methods. The results show that the level of attitude among the practitioners is high ( mean $=4.15$, standard deviation $=0.39$ ). Interviews with the practitioners showed that they practised a positive attitude when conducting juvenile rehabilitation programmes. However, juvenile informants said that the practitioners are negative towards them. Therefore, rehabilitation practitioners need to be given a training in terms of development and application of a positive rehabilitation attitude. The findings of this study have implications for policy and the practice of a positive attitude among practitioners of juvenile rehabilitation programmes in Malaysia.
\end{abstract}

Keywords: Social Work, Social Services, Practitioner's Attitude, Rehabilitation Programme, Juvenile

\section{Introduction}

The implementation of juvenile rehabilitation programmes in Malaysia aims to rehabilitate offenders who have committed crimes, in terms of their physical, cognitive, social and educational skills. Based on the Children Act (2001), they are entitled to education, care and 
protection. Among the organisations that handle juvenile rehabilitation programmes include the Malaysian Social Welfare Department and the Malaysian Prisons Department.

To ensure the effectiveness of these juvenile rehabilitation programmes, there are several criteria that need to be taken into account. Among these criteria are the provision and quality of rehabilitation activities or modules, the adequacy of financial resources as well as the adequacy and suitability of facilities at the rehabilitation centre. In addition, the attitude of the practitioners while conducting the programmes for the juvenile offenders is also important to ensure that the objectives of the juvenile rehabilitation programme are achieved. Therefore, the objective of this study is to:

- evaluate the implementation of juvenile rehabilitation programmes in terms of the practices carried out by rehabilitation practitioners.

Attitude is a feeling and thought that motivates a person to act, showing whether he likes something or dislikes it. As an example, commitment to a job is one of the components affecting one's actions. Thus, the attitude of an employee towards his job may be positive or negative. The same is true in the context of this study which includes aspects related to rehabilitation practitioners' behaviour and attitude (Hezzrin \& Norsuhaily, 2019, Tucker \& Yuen, 2019). Based on past studies, there is a lack of research carried out on rehabilitation practitioners involved with the implementation of rehabilitation programmes (Dowden \& Andrews, 2004; Makarios et al., 2016). Most previous studies on moral rehabilitation programmes focus more on the offenders undergoing the moral rehabilitation programmes rather than the practitioners implementing the programmes (Dowden \& Andrews, 2004; Makarios et al., 2016). The implementation of an effective rehabilitation programme is also influenced by those who conduct the programme.

According to Dowden and Andrews (2004), a offender who undergoes rehabilitation can change for the better or vice versa based on how the process of rehabilitation is implemented, the services provided and what occurs around him during the recovery process. Changes in the behaviour of a offender who is undergoing moral rehabilitation are influenced by factors such as how a case worker and/or practitioner deals with them. This shows that the effectiveness of the juvenile rehabilitation process is also influenced by the practitioner's attitude when carrying out activities under the juvenile rehabilitation programme.

The attitude that should be possessed by rehabilitation practitioners is one of commitment. Commitment means an attitude where one feels obligated or emotionally impelled. According to Lambert et al. (2007), practitioners who are committed can influence the outcome of the implementation of rehabilitation programmes. However, there are still many rehabilitation practitioners who do not play a role as a competent practitioner. This is because most of them still do not have an in-depth understanding about their role in helping clients or trainees who are undergoing moral rehabilitation (Lambert et al., 2007). As a result, there are many incidents where rehabilitation practitioners are rude and do not have a good relationship with the offenders/trainees. A practitioner should also have empathy towards clients undergoing rehabilitation programmes (Zalesky, 2016). Empathy is a feeling that is isomorphous to those of the other person, sympathy, empathic concern, and compassion (Vyskocilova, Prasko \& Slepecky, 2011). Therefore, to be a professional rehabilitation social worker, the nature of empathy must be present. This is because the nature of empathy will enable one to be sensitive to the feelings of the client (Zalesky, 2016; Normah et al., 2014). 
Furthermore, being responsible is also one of the important attitudes that should be inculcated among moral rehabilitation practitioners (Young et al., 2009). They should be responsible for any action taken against clients, their employees, co-workers and employers. An irresponsible attitude will cause conflict in the organisation or the implementation of a rehabilitation programme. A responsive attitude among practitioners in handling criminal cases among offenders is also seen to play a role in ensuring the effectiveness of rehabilitation programmes. In the context of moral rehabilitation, practitioners should be responsive when there are discussions or complaints from offenders. The study of Dirkzwagera and Kruttschnitt (2012) states that Dutch prisons oriented towards rehabilitation have practitioners who are more responsive and friendly to offenders. However, in contrast, the British prison rehabilitation centres are punitive in nature, where their practitioners are often controversial and unresponsive. The results from the study show that a more responsive attitude in the practitioners towards the offenders is more effective in the rehabilitation process.

Based on previous studies on the type of attitude that should be practised by practitioners, it has been shown that attitude influences the effectiveness of the rehabilitation process of offenders. Therefore, the objective of this study is to evaluate the attitude of practitioners in juvenile rehabilitation institutions in Malaysia. This study is important to determine the extent to which a positive attitude is practised among juvenile rehabilitation practitioners. In addition, this study can suggest improvements in terms of the formation and application of a positive attitude among rehabilitation practitioners. This is to ensure that juvenile who undergo moral rehabilitation programmes achieve an effective outcome from the rehabilitation process, in the aspects of improved discipline, good attitudes and values, as well as improved education and life skills (Hezzrin \& Norsuhaily, 2020; Barton \& Butt, 2008).

\section{Theoretical Framework}

Based on the Theory of Behavior by Ajzen (1991), an individual's attitude will influence behaviours and determine job performance. A positive attitude among employees will create harmony. A good attitude also creates good relationships as well as become an example to others. In the context of rehabilitation, a good and positive attitude among rehabilitation practitioners have a positive impact on juvenile (Pauzi, 2019).

This matter is also closely related to the Learning Theory. This is because the theoretical features of social learning emphasize that the main elements of learning are observation and imitation, and that model behaviour can be learned through language, example, values and others. Thus, the theoretical aspect of this study is guided by behavioural theory and learning theory in which both theories emphasize the elements of individual attitudes that influence the behaviour of people around them. This means that the attitude of rehabilitation practitioners is one of the factors in determining the effectiveness of the implementation of juvenile rehabilitation programmes.

\section{Methodology}

The design of this study is a mixed-method of Sequential Design. This method combines the use of quantitative and qualitative. This study involves two phases, namely a quantitative study conducted which is then followed by a qualitative study.

This study was carried out in rehabilitation centres in Peninsular Malaysia. The sample of this study consisted of practitioners who are involved in rehabilitation programmes. In addition, 
the sample of this study also included juvenile offenders who are undergoing a process of rehabilitation. The sample size in the quantitative study was 95 respondents. Meanwhile, for the qualitative study, it involved nine practitioners and eight juvenile offenders. The purposive sampling technique as used for the quantitative and qualitative studies.

Quantitative study data were collected through a survey and qualitative research data were collected through the interview method. The quantitative research instrument used was a questionnaire distributed to respondents. For the qualitative data, interviews were used as the research instrument. The interview sessions were conducted with the practitioners and the juvenile offenders, and were carried out until data were saturated. Finally, the quantitative data obtained were analysed using Statistical Package for the Social Sciences (SPSS) software. Quantitative data is presented in frequency and percentage distribution, while qualitative data were analysed using thematic methods.

\section{Findings}

The findings of the study show that the attitude of practitioners of juvenile rehabilitation programmes is at a high level (mean $=4.15, \mathrm{SD}=0.39$ ). The item "Being non-judgmental towards trainees" recorded the highest mean score of 4.28 (standard deviation $=0.52$ ). The item with the lowest mean score was "Professional when implementing tasks under the rehabilitation programme" which recorded a mean score of 3.90 (standard deviation $=0.57$ ).

Table 1 The self-evaluation carried out regarding the attitude during implementation of rehabilitation programmes $(n=95)$.

\begin{tabular}{|l|c|c|c|}
\hline \multicolumn{1}{|c|}{ Item } & $\begin{array}{c}\text { Mean } \\
\text { score }\end{array}$ & $\begin{array}{c}\text { Standard } \\
\text { Deviation }\end{array}$ & Level \\
\hline $\begin{array}{l}\text { Committed in conducting rehabilitation } \\
\text { programme. }\end{array}$ & 4.01 & 0.50 & High \\
\hline $\begin{array}{l}\text { Responsive in conducting rehabilitation } \\
\text { programme. }\end{array}$ & 4.00 & 0.53 & High \\
\hline $\begin{array}{l}\text { Professional in conducting rehabilitation } \\
\text { programme. }\end{array}$ & 3.90 & 0.57 & Moderate \\
\hline Empathetic towards the juvenile offenders. & 4.14 & 0.56 & High \\
\hline Judgmental of the juvenile offenders. & 4.28 & 0.52 & High \\
\hline Patient in conducting rehabilitation programme. & 4.16 & 0.56 & High \\
\hline \multicolumn{1}{|c|}{ Total } & 4.15 & 0.39 & High \\
\hline
\end{tabular}

The findings show that the rehabilitation practitioners were positive when implementing juvenile rehabilitation programmes. They showed commitment to ensure that the objectives of the rehabilitation centre are achieved. They were also always responsible in carrying out juvenile rehabilitation activities. In addition, they had a positive attitude as they have empathy, do not judge and were patient when handling trainees who were undergoing moral rehabilitation programmes. 
In order to get an explanation of the quantitative findings on the attitude of the practitioners, an interview session was conducted with both the practitioners and the juveniles. Based on the results of a qualitative study with the practitioners about their self-esteem, three main themes were assessed, namely role model, self-efficacy and empathy. In contrast, in the qualitative findings from the juveniles, the main theme was being emotionally less controlled (Table 2).

Table 2 Themes and sub-themes of qualitative findings from implementers and trainees

\begin{tabular}{|l|l|}
\hline \multicolumn{2}{|c|}{ Themes } \\
\hline Role model & \multicolumn{1}{c|}{ Juvenile offenders } \\
\hline Self-efficacy & Emotionally less controlled \\
\hline Empathy & \\
& \\
\hline
\end{tabular}

\section{Role Model}

A role model is a person whose behaviour can be used as an example or can be emulated by other individuals or groups. A role model must be act positive as they will become a role model especially for teenagers or young people. In the context of rehabilitation, practitioners are constantly in touch or interact with the juveniles. Therefore, the practitioners should show a positive attitude when working with youths within the juvenile justice system.

In the qualitative study conducted, it was found that the practitioners have shown themselves to be a good role model to the offenders. A total of eight practitioners stated that they need to set a good example or need to be role models to juvenile offenders. As stated by informant B, "I show a good attitude first to be a role model for the youth here". Informant B stated that a good attitude should be instilled in oneself first so that they can be an example to the youth offenders.

Informant $F$ stated that negative behaviour should be avoided and practitioners should show a good attitude, such as by helping, cooperating and being patient. This good attitude will be followed by the juveniles. "For me, I don't show bad behaviour in front of them so that we can be an example to them, and be the role model for them. We show good things like cooperation, helping each other and being patient with them so that they can follow". (Informant F)

\section{Self-efficacy}

Self-efficacy is a belief in the ability of one's self to organise and perform the actions required to deal with a variety of situations. In this study, high self-efficacy is also seen to be necessary in every practitioner to ensure the success of rehabilitation programmes. A total of five practitioner's informants stated that high self-efficacy should be practised during teaching and rehabilitation.

Informant $H$ stated that in delivering lessons to youth offenders, practitioners or instructors need to have high self-confidence or self-efficacy so that the process of moral rehabilitation is effective. Good advice must be delivered with confidence by the practitioners so that it is accepted by the offenders. Informant H said, "I need to be confident to deliver lessons to them because it is my job to impart good knowledge to them". 
Informant $C$ also stated that the practitioners should have high self-efficacy while carrying out their duties so that the offenders participate confidently and accept positively the recovery process that they undergo. "I think we as rehabilitation officers need to be equipped with a good attitude such as self-confidence, high efficiency so that these boys are also confident in us and they can accept what they are doing now". (Informant C)

\section{Empathy}

Apart from self-efficacy, empathy is also one of the attitudes practised by practitioners. Empathy is a person's ability to delve into and understand the feelings or emotions of others. Empathy is one of the important characteristics that must be present in every practitioner in the process of helping a trainee. Practitioners must be able to understand the problems that the trainees may try to hide, so to ensure they are not left with negative feelings/actions.

The qualitative analysis showed that six practitioners agreed on the importance of empathy in handling juveniles. With this attitude, the practitioners will try to understand the problems faced by the juveniles. The practitioners will also try to help in solving their problems. One of the statements made by the study informant about this is as follows.

"For me, we need to understand the character of the juveniles, we need to understand their problems. We also need to know how to approach them. How to educate them. We try to help in whatever way is necessary so that they do not feel burdened with their problems." (Informant G)

By being empathetic, the practitioners will easily understand the juvenile's problems. It leads to a forgiving attitude towards the trainee. Informant $C$ said the juveniles who had committed a crime/offense may have done so because they made a mistake or did not think clearly when committing the offense, "We should have an attitude of forgiveness. The reason may be that he was wrong. They are still young".

The analysis of the interviews with the practitioners showed that results pertaining to the themes of role model, self-efficacy and empathy strengthen the quantitative findings, namely the high mean score levels in terms of the self-attitude of rehabilitation practitioners. Thus, this clearly shows that rehabilitation practitioners are indeed adopting a positive attitude while implementing rehabilitation programmes.

However, the findings of the interview study from the practitioners were contradictory to the explanation obtained from the interviews with the juvenile informants. From the interviews conducted, it was found that the juveniles did not like most of the rehabilitation practitioners' attitudes. The theme analysis from the juvenile interviews is emotionally less controlled.

\section{Emotionally Less Controlled}

Emotions are seen as a characteristic of the soul of an individual who exhibits strong feelings towards something, whether positive or negative. However, when a person does not know how to manage their emotions well, there will be uncontrolled emotions. For example, angry emotions.

In this study, a total of six informants among the juvenile offenders stated that most of the practitioners were less able to control their emotions when dealing with juveniles. The practitioners are easily angered despite the mistakes being small, as told by informant Di, "If there is something wrong, he is emotional although it is just a little mistake". According to the juvenile informants, due to the practitioners' uncontrolled emotions, they would sometimes overly punish or fine the trainees. "He is emotional no matter what. He is angry, he is in a bad mood, acts outrageously" (Informant Ci). 
Another informant stated that the practitioners would easily get emotional and often punished juvenile trainees who made mistakes without investigating the issue in more depth. "Sometimes he loses patience with the boy. His emotions are out of control. He seems impatient, seems to have lost his temper with us. They say these boys are all stubborn" (Informant Fi). Rehabilitation practitioners should control their emotions when handling the juveniles, especially when problems arise. The practitioners should also discuss and give advice to the juvenile's undergoing rehabilitation. In the cognitive model, adolescent caregivers need to manage their emotions as it affects the development of the adolescents.

\section{Discussion}

This study has shown that the level of self-esteem of rehabilitation practitioners in Malaysia is at a high level. Explanations given by the practitioners through the interviews also show that they practice good values when conducting juvenile rehabilitation programmes. They adopt a positive attitude for the positive development of juvenile offenders. However, it differs from the explanations given by the juveniles who expressed their dissatisfaction and felt uncomfortable with most of the rehabilitation practitioners' attitudes. They said most practitioners were less professional when conducting the rehabilitation programmes. The practitioners were often easily upset and did not care about them. The opinions of these juveniles are also important and should be taken into consideration. In addition, the less professional attitude of rehabilitation practitioners has influenced the juveniles' behaviour. Based on the findings from the interview with the juveniles, the practitioners have sometimes punished the trainees without fully discussing the issues that had risen.

Rehabilitation practitioners should be sensitive to the offender's emotions or feelings, for which high empathy is required (Zalesky 2016). In this study, they also once labeled juveniles as naughty teenagers. The labelling showed a less professional attitude in implementing rehabilitation. This is in line with the Theory of Behaviour where individual actions and evaluations are influenced by the individual's own attitude towards something. The learning theory also states that an individual's behaviour can influence the behaviour of the surrounding individuals. Moreover, in the cognitive model, adolescent caregivers need to manage their emotions as it affects the development of the adolescents (Norsuhaily \& Hezzrin 2020). Therefore, rehabilitation implementers should always be positive for the effective implementation of the juvenile rehabilitation process.

The findings of this study have specifically focused on the rehabilitation practitioner's attitude compared to previous studies that only discussed this aspect in general. This study also looks at different perspectives from previous studies by linking the effectiveness of juvenile rehabilitation programmes with behavioural theory and learning theory in which the offenders observe and learn from the behaviours around them throughout the recovery process. If the practitioners handle the trainees in a positive way, then the offenders would also accept the recovery process positively.

\section{Recommendations and Conclusions}

Juvenile rehabilitation practitioners should always display good attitudes and values while handling juveniles who are undergoing the process of moral rehabilitation. Apart from the application of a positive attitude such as being committed, responsive, professional, empathatic, non-judgmental, patient, having high self-efficacy and being a role model, rehabilitation practitioners must also adhere to professional values that need to be practised among social workers based on the NASW 1996 code of ethics. In this code of ethics, there 
are six professional values that need to be practiced among social workers. Such professional values consist of elements of service, social justice, dignity and individuality, the importance of human relations, integrity and competence. For the service element, social workers need to help individuals in need and solve social problems. Social workers need to have the courage to challenge social injustice and respect the dignity and natural self-esteem of individuals.

Professional values should also be applied in all areas of social work including juvenile rehabilitation. In order to facilitate the process of accepting juvenile trainees to accept the rehabilitation process, implementers need to know about the code of ethics NASW (1996) as well as practise them while carrying out their work. Therefore, rehabilitation implementers need to adopt a positive attitude and practice professional values so that rehabilitation programmes are effective for juvenile trainees. The professional values also emphasize the importance of appreciating human relations and always behaving in trust in carrying out duties. Social workers also need to be competent in their field and constantly develop and enhance their professional expertise from time to time. These values need to be applied by every rehabilitation implementer through the attitude exhibited to the trainees.

Table 3 Professional Values according to NASW Code of Ethics (1996)

\begin{tabular}{|l|l|}
\hline \multicolumn{1}{|c|}{ Values } & \multicolumn{1}{c|}{ Description } \\
\hline Services & $\begin{array}{l}\text { Helping individuals in need and solving } \\
\text { social problems }\end{array}$ \\
\hline Social justice & Challenging social injustice \\
\hline Individual dignity and value & $\begin{array}{l}\text { Respect the dignity and natural self- } \\
\text { esteem of the individual }\end{array}$ \\
\hline The importance of humanitarian relations & $\begin{array}{l}\text { Appreciate the importance of } \\
\text { humanitarian relations }\end{array}$ \\
\hline Integrity & Behaving in trust \\
\hline Efficiency & $\begin{array}{l}\text { Competent in his field and develop and } \\
\text { enhance professional expertise }\end{array}$ \\
\hline
\end{tabular}

Therefore, rehabilitation centres and the Malaysian Social Welfare Department need to take proactive action to develop positive attitudes and values among rehabilitation practitioners. At the administrative level of the rehabilitation centres, and the Social Welfare Department in particular, it is necessary to take the initiative by providing training and development such as programmes, courses or workshops that explain the importance of ethical practice as outlined in the NASW Code of Ethics 1996. The Malaysian Social Welfare Department is encouraged to organise programmes describing the importance and ways of managing emotions, to improve the emotional intelligence of the practitioners. Emotional management programmes can include elements of self-awareness, self-control, empathy and socialising. The administration of the rehabilitation centres must also constantly monitor the implementers so that they practice positive attitudes and values when carrying out their duties as practitioners of rehabilitation. By utilising this suggestion, policymakers can 
continue to monitor and improve the care provided in juvenile justice facilities. This is to ensure the effective implementation of rehabilitation programmes for juvenile offenders.

\section{References}

Ajzen, I. (1988). Attitudes, Personality and Behavior. Chicago: Dorsey Press

Barton, W. H., \& Butts, J. A. (2008). Building on Strength: Positive Youth Development in Juvenile Justice Programs. Chicago: Chaplin Hall Center for Children.

Children Act.. (2001). Akta Kanak-Kanak 2001 (Akta 611): Law Review Commissioner. Putrajaya Percetakan Nasional Malaysia Berhad.

Dirkzwagera, A. J. E., \& Kruttschnitt, C. (2012). Prisoners' perceptions of correctional officers' behavior in English and Dutch prisons. eJournal of Criminal 40(5): 404-412.

Dowden, C., \& Andrews, D. A. (2004). The Importance of Staff Practice in Delivering Effective Correctional Treatment: A Meta- Analytic Review of Core Correctional Practice. International Journal of Offender Therapy and Comparative Criminology 48(2): 203-214.

Pauzi, H. M., \& Abu Bakar, N. (2020). The Competency of Rehabilitation Practitioner in Conducting Juvenile Rehabilitation Programme . International Journal of Advanced Science and Technology 29 (7):388-397

Lambert, E. G., Paoline, E. A., Hogan, N. L., \& Baker, D. N. (2007). Gender Similarities and Differences in Correctional Staff Work Attitudes and Perceptions of the Work Environment. Western Criminology Review 8(1): 16-31.

Makarios, M., Lovins, L., Latessa, E., \& Smith, P. (2016). Staff Quality and Treatment Effectiveness: An Examination of the Relationship between Staff Factors and the Effectiveness of Correctional Programs. Justice Quarterly 33(2):348-367.

Noh, N. A., Abdul Wahab, H., \& Abu Bakar Ah, S. H. (2014). Kualiti Perkhidmatan Kesihatan Awam yang Diterima oleh Buruh Asing: Kajian Kes di Lembah Klang. Jurnal Sains Kesihatan Malaysia 12(1): 47-56

Abu Bakar, N., Al-smadi, M. S., \& Pauzi, H. M. (2020). Stress and Issues of Mental Health for Parent with Special Needs Children. International Journal of Advanced Science and Technology 29 (7): 471-478.

Pauzi, H. M. (2019). Positive Youth Development as an Indicator of the Effectiveness of Juvenile Rehabilitation Program. International Journal of Academic Research in Business and Social Sciences 9(7), 909-914.

Tucker, S. C., \& Yuen, H. K. (2019). Attitudes toward rehabilitating inmates among occupational therapy students in the United States. Journal Educational Evaluation for Health Professions 16(6).

Vyskocilova, J., Prasko, qJ. \& Slepecky, M. (2011). Empathy in cognitive behavioral therapy and supervision.2011. Act Nerv Super Rediviva 53(2): 72-83.

Young, J. L., Antonio, M. E., \& Wingeard, L. M. (2009). How staff attitude and support for inmate treatment and rehabilitation differs by job category employee training curriculum 'Reinforcing Positive Behavior': An evaluation of findings from Pennsylvania's Department of Corrections'. Journal of Criminal Justice 37 :435-441.

Zalesky, K. (2016). Empathy in social work. Contemporary Behavioral Health Care 2 (1): 48:53 